\title{
Pharmacokinetics and the optimal regimen for levofloxacin in critically ill patients receiving continuous hemodiafiltration
}

\author{
Takeshi Wada1*, Masaki Kobayashi², Yuichi Ono ${ }^{1}$, Asumi Mizugaki ${ }^{1}$, Kenichi Katabami', Kunihiko Maekawa', \\ Daisuke Miyamoto', Yuichiro Yanagida', Mineji Hayakawa', Atsushi Sawamura', Ken Iseki ${ }^{2,3}$ and Satoshi Gando ${ }^{1}$
}

\begin{abstract}
The aim of this study was to establish the pharmacokinetics of levofloxacin (LVFX) and determine the optimal dose of this drug in critically ill patients receiving continuous hemodiafiltration (CHDF). The results of in vivo and in vitro studies showed the pharmacokinetics of LVFX total clearance $\left(\mathrm{CL}_{\text {total }}\right)$ according to the creatinine clearance $\left(\mathrm{CL}_{\mathrm{Cre}}\right)$, dialysate flow $\left(Q_{D}\right)$, and ultrafiltrate flow $\left(Q_{F}\right)$, to be as follows: $C_{\text {total }}(1 / h)=0.0836 \times \mathrm{CL}_{\text {Cre }}(\mathrm{ml} / \mathrm{min})+0.013 \times$ body weight $(\mathrm{kg})+0.94\left(\mathrm{Q}_{D}+\mathrm{Q}_{F}\right)(\mathrm{I} / \mathrm{h})$. The optimal dose of LVFX was expressed by the following formula: $50 \times C L_{\text {total }}$. These results demonstrate that the usual dose of LVFX (500 mg) was sufficient for the patients evaluated in this study.
\end{abstract}

Keywords: Levofloxacin, Pharmacokinetics, Continuous hemodiafiltration, Clearance

\section{Findings}

The pharmacokinetics of levofloxacin (LVFX) total clearance $\left(\mathrm{CL}_{\text {total }}\right)$ were determined based on the creatinine clearance $\left(\mathrm{CL}_{\mathrm{Cre}}\right)$, dialysate flow $\left(\mathrm{Q}_{\mathrm{D}}\right)$, and ultrafiltrate flow $\left(\mathrm{Q}_{\mathrm{F}}\right)$, as follows:

$$
\begin{aligned}
\mathrm{CL}_{\text {total }}(\mathrm{l} / \mathrm{h})= & 0.0836 \times \mathrm{CL}_{\mathrm{Cre}}(\mathrm{ml} / \mathrm{min})+0.013 \\
& \times \text { body weight }(\mathrm{kg})+0.94\left(\mathrm{Q}_{\mathrm{D}}+\mathrm{Q}_{\mathrm{F}}\right) \\
& \times(\mathrm{l} / \mathrm{h})
\end{aligned}
$$

\section{Introduction}

Critically ill patients often require continuous hemodiafiltration (CHDF) as a result of acute kidney injury induced by severe sepsis. Levofloxacin (LVFX) is widely used for treatment in these patients. However, the pharmacokinetics (PK) of LVFX during CHDF are not uniform, as CHDF is performed using various combinations of the dialysate flow $\left(\mathrm{Q}_{\mathrm{D}}\right)$ and ultrafiltrate flow $\left(\mathrm{Q}_{\mathrm{F}}\right)$. The aim of the present study was to estimate the PK of LVFX in patients receiving CHDF and determine the optimal dose of LVFX for this patient population.

\footnotetext{
*Correspondence: tacchi1112@yahoo.co.jp

'Division of Acute and Critical Care Medicine, Department of Anesthesiology and Critical Care Medicine, Hokkaido University Graduate School of Medicine, N15W7, Kita-ku, Sapporo 060-8638, Japan

Full list of author information is available at the end of the article
}

\section{Methods}

Approval for this study was obtained from the institutional review board, - The Ethics Committee of Hokkaido University School of Medicine (011-0107). Informed consent for this study was obtained from the patients' next of kin.

\section{In vitro study}

A CHDF circuit model (JUN-600, JUN-KEN MEDICAL Co., Tokyo, Japan) was established using a cellulose triacetate hollow fiber $1.1 \mathrm{~m}^{2}$ hemofilter (UT-1100, Nipro, Japan). The machine was primed with fresh frozen plasma (FFP), and $100 \mathrm{mg}$ of LVFX were added to the circuit. The FFP flow was fixed at $150 \mathrm{ml} / \mathrm{min}$, and the CHDF conditions were as follows: the $\mathrm{Q}_{\mathrm{D}}$ was defined from 0,1 , and $2 \mathrm{l} / \mathrm{h}$; the $\mathrm{Q}_{\mathrm{F}}$ was defined from 0,1 , and 2 $1 / h$, independent of $Q_{D}$. Samples were obtained from the prehemofilter and ultrafiltrates at 15, 30, 45, and $60 \mathrm{~min}$ after the start of CHDF. The sieving coefficient (SC) values were calculated based on the LVFX concentrations in the filtrates and prehemofilter. The levels of clearance $(\mathrm{CL})$ via $\mathrm{CHDF}\left(\mathrm{CL}_{\mathrm{CHDF}}\right)$ were obtained for the product of $\mathrm{SC}$ and $\left(\mathrm{Q}_{\mathrm{D}}+\mathrm{Q}_{\mathrm{F}}\right)$ and then were plotted, respectively. 




\section{In vivo study}

Four patients with acute kidney injury were administered LVFX during CHDF (ACH- $\Sigma$, Asahi Kasei Medical. Co., Tokyo, Japan). The hemofilter used in the in vivo study was a polysulfone hollow fiber $1.3 \mathrm{~m}^{2}$ hemofilter (EXCELFLO AEF-13, Asahi Kasei Medical. Co., Tokyo, Japan). Replacement fluid was connected to the post-filter blood line. The $24 \mathrm{~h}$ creatinine clearance values were accurately measured based on the urine and serum creatinine levels and the $24 \mathrm{~h}$ urine output. The LVFX dose was set at 500 $\mathrm{mg} /$ day for all patients. Blood samples were collected before the administration of LVFX and at 1, 2, 6, 12, and 24 hours after the start of drug administration. The concentration of LVFX was determined according to a high-performance liquid chromatography method, and a pharmacokinetic analysis was performed using a nonlinear least-squares regression program. The parameters were calculated by employing a two-compartment open model with a constant rate of infusion. The area under the concentration-time curve (AUC) was determined based on the trapezoidal rule. The optimal dose of LVFX was calculated based on the following relational expression:

$$
\mathrm{CL}_{\text {total }}=\text { dose of drug } / \mathrm{AUC}
$$

\section{Results}

The $\mathrm{CL}_{\mathrm{CHDF}}$ obtained via interpolation into a simple linear regression of $\mathrm{CL}_{\mathrm{CHDF}}$ against $\left(\mathrm{Q}_{\mathrm{D}}+\mathrm{Q}_{\mathrm{F}}\right)$ closely correlated with the experimental data (Figure 1). The PK of LVFX clearance $\left(\mathrm{CL}_{\text {vivo }}\right)$ was determined based on the creatinine clearance $\left(\mathrm{CL}_{\mathrm{Cre}}\right)$ and body weight $(\mathrm{BW})$, according to previous study [1]. The LVFX total clearance $\left(\mathrm{CL}_{\text {total }}\right)$ in a patient receiving $\mathrm{CHDF}$ was calculated as follows:

$$
\begin{aligned}
\mathrm{CL}_{\text {total }}(\mathrm{l} / \mathrm{h})= & \mathrm{CL}_{\text {vivo }}+\mathrm{CL}_{\mathrm{CHDF}} \\
= & 0.0836 \times \mathrm{CL}_{\mathrm{Cre}}(\mathrm{ml} / \mathrm{min})+0.013 \\
& \times \mathrm{BW}(\mathrm{kg})+0.94 \times\left(\mathrm{Q}_{\mathrm{D}}+\mathrm{Q}_{\mathrm{F}}\right)(\mathrm{l} / \mathrm{h})
\end{aligned}
$$

The values of predictive $\mathrm{CL}_{\text {total }}$ were calculated based on this formula. Table 1 shows the characteristics of the patients. We were unable to calculate the predictive $\mathrm{CL}_{\text {total }}$ in patient No. 3 because the urine creatinine level was not examined in this case. The LVFX concentrationtime curve is shown in Figure 2, and the pharmacoki-

\begin{tabular}{|c|c|c|c|c|c|c|c|c|}
\hline Patient & Sex & Age (years) & Diagnosis & Weight (kg) & APACHE II & The cause of AKI & $\begin{array}{l}\text { The value of Cre } \\
\text { on admission to } \\
\text { ICU (mg/dl) }\end{array}$ & $\begin{array}{l}\text { Duration of } \\
\text { CHDF (days) }\end{array}$ \\
\hline 1 & Male & 75 & Ruptured AAA & 70.7 & 31 & Hemorrhagic shock & 1.32 & 66 \\
\hline 2 & Male & 59 & $\mathrm{OHCA}$ & 88.9 & 42 & PCAS & 0.98 & 5 \\
\hline 3 & Male & 46 & $\begin{array}{l}\text { Congenital } \\
\text { heart disease }\end{array}$ & 50.0 & 21 & $\begin{array}{l}\text { Major cardiac } \\
\text { operation }\end{array}$ & 0.69 & 45 \\
\hline 4 & Male & 58 & $M L$ & 58.3 & 41 & Drug induced & 2.04 & 38 \\
\hline Mean \pm SE & & $59.5 \pm 6.0$ & - & $70.0 \pm 8.5$ & $33.8 \pm 4.9$ & - & $1.25+0.29$ & $38.5+12.7$ \\
\hline BUN (mmol/l) & $\begin{array}{l}24 \mathrm{~h} \mathrm{CL}_{\text {cre }} \\
\text { (ml/min) }\end{array}$ & $Q_{D}(I / h)$ & $\mathrm{Q}_{\mathrm{F}}(\mathrm{l} / \mathrm{h})$ & $\begin{array}{l}\text { Predictive } \\
\mathrm{CL}_{\text {total }}(\mathrm{I} / \mathrm{h})\end{array}$ & \multicolumn{4}{|c|}{$\begin{array}{l}\text { Calculated optimal } \\
\text { dose of LVFX (mg) }\end{array}$} \\
\hline 42 & 3.4 & 1.0 & 2.0 & 4.0 & 200 & & & \\
\hline 43 & 0.9 & 1.0 & 2.0 & 4.0 & 200 & & & \\
\hline 40 & - & 1.0 & 2.0 & - & - & & & \\
\hline 32 & 3.4 & 0.5 & 1.5 & 2.9 & 145 & & & \\
\hline $39.3 \pm 5.0$ & $2.6 \pm 0.8$ & $0.86+0.13$ & $1.88+0.13$ & $3.6 \pm 0.4$ & $182+18.3$ & & & \\
\hline
\end{tabular}
netic parameters of LVFX are presented in Table 2. The AUC was $73.9 \pm 13.8(\mathrm{mg} / \mathrm{l} \mathrm{h})$.

Table 1 Characteristics of the patients

AAA abdominal aortic aneurysm, OHCA out-of-hospital cardiac arrest, ML malignant lymphoma, APACHE II Acute Physiology and Chronic Health Evaluation II score, AKI acute kidney injury, PCAS post-cardiac arrest syndrome, Cre creatinine, ICU intensive care unit, CHDF continuous hemodiafiltration, BUN blood urea nitrogen, $\mathrm{CL}_{\text {cre }}$ creatinine clearance, $\mathrm{CL}_{\text {total }}$ total clearance, $\mathrm{QD}$ dialysate flow, $\mathrm{QF}$ ultrafiltrate flow, $\mathrm{LVFX}$ levofloxacin, $\mathrm{SE}$ standard error. 


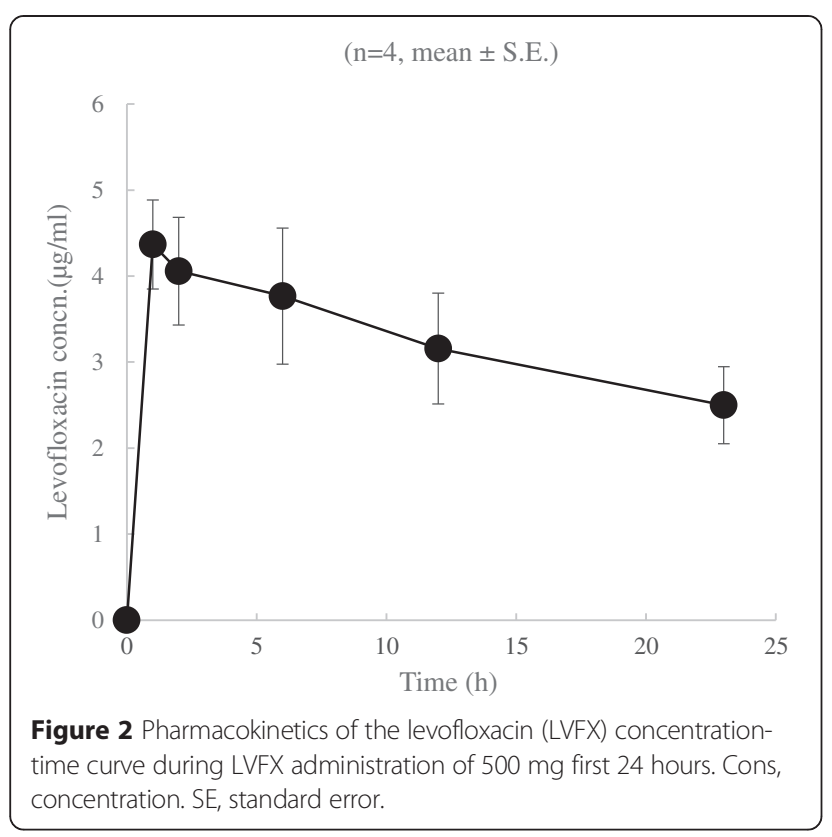

\section{Discussion}

The ratio of AUC/minimum inhibitory concentration (MIC) is a well-known important PK and pharmacodynamics predictor of the clinical efficacy of fluoroquinolones, including LVFX. Previous studies suggest that the AUC/MIC of $\geq 100$ (h) is required in compromised patients or those exhibiting severe Gram-negative rod or staphylococcal infection [2-4]. In addition, the MIC for $90 \%$ of tested strains against most common Gram-negative aerobic pathogens is $<0.5(\mu \mathrm{g} / \mathrm{ml})$ [5]. Therefore, we determined the target AUC to be $\geq 50$ and the optimal dose of LVFX to be $50 \times \mathrm{CL}_{\text {total. }}$. Hence, the LVFX concentrations reached higher than optimal concentrations, and infection could therefore be successfully controlled in these patients.

Three factors affect the PK during CHDF as follows: 1) pore size and protein binding fraction of the drug; 2 ) molecular size; 3) $\mathrm{Q}_{\mathrm{D}}$ and $\mathrm{Q}_{\mathrm{F}}$ in the CHDF protocol [6]. The triacetate and polysulfone membranes used in this

Table 2 Pharmacokinetic parameters of levofloxacin in the patients receiving continuous hemodiafiltration

\begin{tabular}{lllll}
\hline Patient & $\mathbf{C L}_{\text {total }}(\mathbf{l} / \mathbf{h})$ & $\mathbf{t}_{\mathbf{1 / 2}}(\mathbf{h})$ & $\mathbf{C}_{\max }(\mathbf{m c g} / \mathbf{m l})$ & AUC $[(\mathbf{m g} / \mathbf{l}) \mathbf{h}]$ \\
\hline 1 & 4.62 & 13.1 & 5.7 & 108.3 \\
2 & 12.3 & 14.4 & 3.0 & 40.8 \\
3 & 6.64 & 28.9 & 4.7 & 75.3 \\
4 & 7.01 & 11.4 & 4.4 & 71.3 \\
Mean \pm SE & $7.63+1.6$ & $16.9+4.0$ & $4.5+0.6$ & $73.9+13.8$ \\
\hline
\end{tabular}

$C L_{\text {total }}$ total clearance, $t 1 / 2$ a half-life, $C_{\max }$ maximum concentration, $A U C$ area under the concentration-time curve, $S E$ standard error. study have large pores and do not have a capacity for drug absorption, characteristics recommended for CHDF. The molecular size of LVFX is $361 \mathrm{Da}$, which is less than that of ciprofloxacin (CPFX) (368 Da). The results of our previous study suggested that the pore size of the hemofilter does not influence the $\mathrm{CL}_{\mathrm{CHDF}}$, likely due to the sufficiently low molecular weight of CPFX [7]. This previous study also indicated that the surface area of the hemofilter with a large amount of $Q_{D}$ possibly affects the clearance of small solutes, such as fluoroquinolones [7]. Therefore, the current results are not applicable in cases in which the $\mathrm{Q}_{\mathrm{D}}$ is large.

The limitations of this study should be addressed. First, the results of a study by Takigawara et al. [1], showing the relationship between the PK of LVFX and the $\mathrm{CL}_{\text {Cre }}$, were based on patients with a normal renal function. These results are not applicable to the present study, as we included patients with more severe kidney injury. Second, the current study included a very small number of patients. Therefore, a larger, more precise clinical study is needed to confirm our results.

\section{Abbreviations}

LVFX: levofloxacin; CHDF: continuous hemodiafiltration; $\mathrm{CL}_{\text {cre: }}$ creatinine clearance; $Q_{D}$ : dialysate flow; $Q_{F}$ : ultrafiltrate flow; $C_{\text {total }}$ : LVFX total clearance; PK: Pharmacokinetics; FFP: fresh frozen plasma; SC: sieving coefficient; $\mathrm{CL}_{\mathrm{CHDF}}$ : clearance by $\mathrm{CHDF} ; \mathrm{CL}_{\text {vivo: }}$ clearance in patients; BW: body weight; AUC: area under the concentration-time curve; MIC: minimum inhibitory concentration; CPFX: ciprofloxacin.

\section{Competing interests}

This study was supported by Daiichi Sankyo Co. Ltd.

\section{Authors' contributions}

TW collected the samples, analyzed the data, drew the diagrams and wrote the manuscript. MK established the experiments, obtained the measurements in the samples and reviewed the manuscript. YN, AM, KK, KM, DM, YY, and AS helped to collect the samples and clinical data. MH helped to establish the experiments and revise the manuscript. KI and SG supervised the research and reviewed the manuscript. All authors read and approved the final manuscript.

\section{Authors' information}

TW is an assistant professor at the Emergency and Critical Care Center at Hokkaido University Hospital. MK is a lecturer at Faculty of Pharmaceutical Sciences, Hokkaido University. YN, AM, KK, KM, DM, YY, MH, and AS work as intensivists at the Emergency and Critical Care Center of Hokkaido University Hospital. Kl is a professor at Faculty of Pharmaceutical Sciences, Hokkaido University and a director at the Department of Pharmacy, Hokkaido University Hospital. SG is a professor at the Division of Acute and Critical Care Medicine, Hokkaido University Graduate School of Medicine.

\section{Acknowledgements}

This study was supported by a Grant-in-Aid for Young Scientists (B) (201325861736) from the Ministry of Education, Science, Sports and Culture of Japan.

\section{Author details}

${ }^{1}$ Division of Acute and Critical Care Medicine, Department of Anesthesiology and Critical Care Medicine, Hokkaido University Graduate School of Medicine, N15W7, Kita-ku, Sapporo 060-8638, Japan. ' Laboratory of Clinical Pharmaceutics \& Therapeutics, Division of Pharmasciences, Faculty of Pharmaceutical Sciences, Hokkaido University, N12W6, Kita-ku, Sapporo 060-0812, Japan. ${ }^{3}$ Department of Pharmacy, Hokkaido University Hospital, N14W5, Kita-ku, Sapporo 060-8648, Japan. 
Received: 10 January 2015 Accepted: 23 April 2015

Published online: 08 May 2015

\section{References}

1. Tanigawara Y, Nomura H, Kagimoto N, Okumura K, Hori R. Premarketing population pharmacokinetic study of levofloxacin in normal subjects and patients with infectious diseases. Biol Pharm Bull. 1995;18:315-20.

2. Nightingale $\mathrm{CH}$, Grant EM, Quintiliani R. Pharmacodynamics and pharmacokinetics of levofloxacin. Chemotherapy. 2000;46 Suppl 1:6-14.

3. Jacobs MR. Optimisation of antimicrobial therapy using pharmacokinetic and pharmacodynamic parameters. Clin Microbiol Infect. 2001;7:589-96.

4. Dalhoff A, Schmitz FJ. In vitro antibacterial activity and pharmacodynamics of new quinolones. Eur J Clin Microbiol Infect Dis. 2003;22:203-21.

5. Rebuck JA, Fish DN, Abraham E. Pharmacokinetics of intravenous and oral levofloxacin in critically ill adults in a medical intensive care unit. Pharmacotherapy. 2002;22:1216-25.

6. Hayakawa M, Ito Y, Fujita I, Iseki K, Gando S. Pharmacokinetics and the most suitable regimen of panipenem/beta mipron in critically ill patients receiving continuous renal replacement therapy: a pilot study. ASAIO J. 2006;52:398-403

7. Hayakawa M, Fujita I, Iseki K, Gando S. The administration of ciprofloxacin during continuous renal replacement therapy: pilot study. ASAIO J. 2009;55:243-5.

\section{Submit your next manuscript to BioMed Central and take full advantage of:}

- Convenient online submission

- Thorough peer review

- No space constraints or color figure charges

- Immediate publication on acceptance

- Inclusion in PubMed, CAS, Scopus and Google Scholar

- Research which is freely available for redistribution 